\title{
Photogenerated Fe(II) accelerates ligand-controlled dissolution rates of iron(hydr)oxides
}

JAGANNATH BISWAKARMA ${ }^{1,2^{*}}$ KYOUNGLIM

KANG $^{3}$, WALTER D. C. SCHENKEVELD ${ }^{4}$,

STEPHAN M. KRAEMER ${ }^{3}$, JANET G. HERING ${ }^{1,2,5}$ AND STEPHAN J. HUG ${ }^{1}$

${ }^{1}$ Eawag, Swiss Federal Institute of Aquatic Science and Technology, Switzerland

${ }^{2}$ ETH, Swiss Federal Institute of Technology Zurich, Switzerland

${ }^{3}$ Dept. of Environmental Geosciences, University of Vienna, Austria

${ }^{4}$ Faculty of Geosciences, Utrecht University, the Netherlands

${ }^{5}$ EPFL,Swiss Federal Institute of Technology Lausanne,

Switzerland

(*correspondence: jagannath.biswakarma@eawag.ch)

Dissolution of iron(III)(hydr)oxides is a key process in the biogeochemical iron (Fe) cycle. Low solubility of iron(III)(hydr)oxides limits the bioavailabiltiy of $\mathrm{Fe}$ in soils and aquatic environments. Recently, we demonstrated that submicromolar concentrations of $\mathrm{Fe}$ (II) led to accelerated ligand-controlled dissolution of iron(III)(hydr)oxides under anoxic conditions at $\mathrm{pH} 6-8.5$. Here, we extend our previous work by studying the effect of photogenarated $\mathrm{Fe}(\mathrm{II})$ on the dissolution of lepidocrocite (Lp) and goethite (Gt) $(1.13 \mathrm{mM})$ with the synthetic ligand EDTA and with the biogenic siderophore desferrioxamine B (DFOB) $(50 \mu \mathrm{M})$.

Our results show that during illumination with UV-A light at $\mathrm{pH} 7.0$ (carbonate buffer), the rate of $\mathrm{Fe}$ (II) production was highest with Gt-EDTA; followed by LpEDTA $>$ Lp-DFOB $>$ Lp $>$ Gt-DFOB $>$ Gt. Under anoxic conditions, photogenerated $\mathrm{Fe}(\mathrm{II})$ accelerated dissolution rates during subsequent dark periods by factors of 10-40 and dissolved $\mathrm{Fe}(\mathrm{III})$ reached $50 \mu \mathrm{M}$ with both DFOB and EDTA. Under oxic conditions, dissolution rates increased by factors of 3-5 only during illumination, but not during subsequent dark periods. With DFOB dissolved Fe(III) reached upto 35 $\mu \mathrm{M}$ after $10 \mathrm{hr}$ illumination, while with EDTA it increased up to $15 \mu \mathrm{M}$ and then decreased to below $2 \mu \mathrm{M}$.

This study suggests that short intermittent illuminations can increase the mobility of $\mathrm{Fe}$ in anoxic layers of shallow ponds, reservoirs and lakes that can be reached by sunlight and in the microenvironments of algal blooms. Furthermore, the photostability of dissolved Fe(III)-ligand complexes is crucial for Fe-mobilization under sunlit oxic conditions. The presented results can be of importance for a better understanding of the behaviour of nutrients and contaminants in redox-dynamic environments. 